\title{
7
}

\section{AND MATCH}

\section{A Framework for Understanding Mixed-Income Outcomes}

\author{
Shomon Shamsuddin
}

\section{Introduction}

Mixed-income housing is a highly prominent approach to housing policy and new housing development in countries and cities around the world. Governments and housing agencies in Australia, Canada, Ireland, the Netherlands, Sweden, the United Kingdom, and the United States, to name a few examples, have proposed or implemented some form of mixed-income housing, in what has been described as "a striking example of international policy transfer" (August, 2008; Bailey et al., 2006; Bridge and Butler, 2011; Chaskin and Joseph, 2015; Darcy, 2010: 1; Musterd and Andersson, 2005; Tsenkova, 2020). In the United States, local and state governments have used regulation and financing tools to construct mixed-income housing since the 1970s; since the early 1990s, the federal government has adopted mixed-income housing as a high-profile strategy for redeveloping public housing through the US Department of Housing and Urban Development's HOPE VI (Housing Opportunities for People Everywhere) program (Brophy and Smith, 1997; Epp, 1996; Popkin et al., 2004; Schwartz and Tajbakjsh, 1997; Shamsuddin, 2017; Vale, 2013; Vale and Shamsuddin, 2014).

For a housing strategy, mixed-income housing has a surprisingly wide range of appeal and support. This may be due, in part, to the involvement of the public sector, private sector, and nonprofit sector in creating mixed-income housing developments. Elected officials have voiced their support for and belief in the value of creating mixed-income communities through government housing programs (Cisneros and Engdahl, 2009; Cuomo, 1999). Planning and housing advocacy organizations encourage governments to pursue mixed-income housing policies (for example, see Metropolitan Council, 2019). Even private developers and investors have spoken favorably about mixed-income development and its prospects for success (Baron, 2009; Harper, 2017).

Prior scholarly work raises important concerns about mixed-income housing but tends to focus on public (or social) housing redevelopment. Studies of selected mixed-income public housing redevelopment sites in the United States generally find that low-income residents report satisfaction with improvements in housing quality and neighborhood safety but also note few positive social interactions with wealthier neighbors (Chaskin and Joseph, 2015; Kleit, 2005; Shamsuddin and Vale, 2017). Case studies of social mixing involving public housing in Canada and Australia observe that public housing tenants may face stigma and oppression, and miss their 
previous homes and the sense of community, which raises questions about the need for social mixes in housing at all (Arthurson, 2002; August, 2016; Ruming et al., 2004). All of these studies draw conclusions about mixed-income housing based on public housing redevelopment but overlook other forms and strategies of the broader phenomenon of residential income mixing.

Additional work suggests that some of the problems observed in mixed-income housing may be due, in part, to the lack of shared understanding of what "mixed income" means. There is no consistent, widely accepted definition of mixed-income housing despite repeated references and discussions of the term over the course of more than 20 years (Brophy and Smith, 1997; Holin et al., 2003; Khadduri and Martin, 1997; Levy et al., 2010; Schwartz and Tajbakjsh, 1997; Vale and Shamsuddin, 2017). Although there is little agreement about how to define the term, mixed-income housing can be characterized by several dimensions: allocation, the proportion of subsidized and unsubsidized units; proximity, the spatial scale of income mixing; tenure, the balance between rental and homeownership units; and duration, the length of time that housing unit affordability is required (Vale and Shamsuddin, 2017). These dimensions directly refer to characteristics of housing, but they do not address residents or the larger geographic context. Further, the dimensions exclusively draw upon public housing redevelopment under the HOPE VI program.

Much academic attention has been devoted to mixed-income redevelopment of public (or social) housing, but there are many forms of mixed-income housing. Besides the HOPE $V I$-style approach to public housing redevelopment, and its successor program called Choice Neighborhoods, there are other housing strategies to bring low-income and higher-income residents together. In the USA, these include tenant-based subsidies (e.g. the Section 8 Housing Choice Voucher program), financial incentives to build affordable housing (such as the Low-Income Housing Tax Credit program), and local regulations that encourage or require affordable housing to be included in new development (e.g. inclusionary zoning). Countries throughout Europe have also developed and implemented a wide variety of housing mix policies that seek to bring different groups of people to live in close proximity to each other (Musterd and Andersson, 2005). Each of these approaches has differences that may have implications for income mixing and expected outcomes.

This chapter presents a new, unified conceptual framework for understanding social mix or mixed-income housing and its potential effects. The framework draws attention to the dynamic process of creating a social or income mix. It identifies several crucial aspects: household income, the moving process, and the neighborhood context, in addition to the housing itself. More specifically, the framework examines which households move to create mixed-income housing, the relative incomes (and other characteristics) of those households, and the neighborhood conditions into which they move. The shorthand description of the framework is "who is moved where." The framework helps distinguish different forms of mixed-income housing and their expected effects. The framework makes several contributions: it draws attention to individual households and neighborhood context, instead of only the physical housing; it integrates households, housing, and neighborhoods into a unified understanding of mixed-income housing; and it applies to multiple forms of income mixing, not just public housing mixed-income redevelopment.

\section{Theory and Literature}

Despite the popularity of mixed-income housing, there is little consensus on how to define what it is. More than 20 years ago, a respected housing policy researcher and an official in the U.S. Department of Housing and Urban Development wrote that, "There is no accepted 
definition of mixed-income housing" (Khadduri and Martin, 1997, 35). They were not alone in their assessment. Analysts and researchers similarly noted that "the term does not carry a formal definition in the housing field" (Brophy and Smith, 1997, 5) and "there is no standard definition in the research literature for what constitutes 'mixed-income' housing" (Holin et al., 2003, 42). An important early article on mixed-income housing presented a series of questions and issues to consider, including that the "term mixed-income housing can refer to many different kinds of housing" (Schwartz and Tajbakhsh, 1997, 73). However, the inclusiveness of the term provides little guidance. More recent work has come to the conclusion that "what counts as mixed income varies considerably" (Levy et al., 2010,16). This work suggests that a definition of mixed-income housing is elusive.

Other housing researchers and practitioners have proposed definitions of mixed-income housing, but little agreement exists here as well. Analysts have suggested that mixed-income housing describes housing developments where $20 \%$ or more of families are below $30 \%$ of area median income (AMI) and 20\% or more are above 50\% AMI (Holin et al., 2003). An experienced developer has stated that mixed-income projects can be described by the proportion of units allocated to different groups and typically consist of one-third public housing, one-third affordable housing, and one-third market-rate units (Baron, 2009). In general, scholars and analysts operate under the idea that "mixed-income housing means a deliberate effort to construct and/or own a multifamily development that has the mixing of income groups as a fundamental part of its financial and operational plans" (Brophy and Smith, 1997, 5). But the lack of clear definition raises questions about the implications of creating mixed-income housing.

\section{Theorized Benefits}

Many scholars and advocates believe that mixed-income housing will create social and political benefits for residents, especially lower-income residents. Prior work theorizes that the presence of higher-income households may lead to (1) increased social capital for low-income residents; (2) direct or indirect role modeling of social norms for work and behavior; (3) informal social control that produces safer communities for all residents; and (4) gains for the broader community through enhanced engagement of political and market forces (Joseph et al., 2007). Similar expected benefits but somewhat different mechanisms for generating those benefits are attributed to mixed-tenure communities in the United Kingdom (Kearns and Mason, 2007).

\section{Dimensions of Mixed-Income housing}

Prior work points to four

dimensions that apply to mixed-income housing projects: 1) distribution of units by subsidy type (allocation); 2) spatial separation of income mix (proximity); 3) distribution of homeownership versus rental units (tenure); and 4) time limits for subsidies that preserve the income mix (duration).

(Vale and Shamsuddin, 2017: 59)

Allocation refers to how housing units are distributed by the type of subsidy in a mixed-income housing project. Allocation encompasses the range of subsidy levels included in the project and the proportions of different income groups represented. The measure of allocation is often expressed in common housing unit subsidy categories: public housing, affordable housing, and market-rate housing. Public housing units are typically occupied by households with incomes 
that are less than $30 \%$ of AMI, affordable housing units are often intended for households with $40-60 \%$ of AMI, and market-rate units may house residents with incomes of $100 \%$ of AMI or higher (Vale and Shamsuddin, 2017).

Proximity refers to the spatial dimension inherent in mixed-income housing, that is, the spatial area in which residents of different income groups will be living together. Residents of different income groups could live in housing units on the same floor of a building, on different floors of the same building, or in different buildings altogether. Closer proximity is expected to create more opportunities for interaction and social relationships among residents than more spatially distant living arrangements (Vale and Shamsuddin, 2017).

Tenure refers to how housing units are distributed according to rental housing or ownership units. Generally, rental units are expected to have more resident turnover than ownership units. Low-income homeownership units in low-income neighborhoods may appeal to residents with long-standing relationships and ties to the area. However, homeownership units in low-income neighborhoods that are advertised for market-rate households may be more likely to attract people who treat housing as a speculative investment, which could also create resident turnover (Vale and Shamsuddin, 2017).

Duration refers to how long the housing units are required or expected to receive subsidies. The length of time may affect the financial and residential stability of mixed-income housing projects. Some forms of mixed-income housing rely on housing unit subsidies that are programmatically time limited, for example, Low-Income Housing Tax Credits. The duration of housing subsidies can have short-term and long-term consequences for those who live in mixed-income housing, how long they live there, what neighborhood opportunities are available, and how well the housing is maintained. Time-limited subsidies may benefit lower-income households in the short-term by providing housing opportunities, while subsidies without time limits may help lower-income households remain in their housing despite neighborhood change (Vale and Shamsuddin, 2017).

These dimensions describe several important factors that housing agencies and housing developers can control when creating mixed-income housing. The dimensions suggest that mixedincome housing can be understood as four types of mixes: (1) socioeconomic mix (allocation of types of subsidy); (2) spatial mix (proximity of different kinds of subsidized units); (3) financial mix (types of tenure made available); and (4) temporal mix (duration of subsidies) (Vale and Shamsuddin, 2017).

It is important to note that this prior work on dimensions was based on administrative HOPE $V I$ data obtained from the US Department of Housing and Urban Development. In other words, the dimensions emerged from an examination of HOPE VI redevelopment of public housing only. Of course, these dimensions may be applied to other forms of mixed-income housing. But some mixed-income projects will not have public housing units or extremely low-income residents.

Further, the dimensions focus on physical (e.g. allocation and proximity) or programmatic (e.g. tenure and duration) characteristics of housing. They overlook other inputs into mixedincome housing. Two important considerations for understanding the variety of types and potential effects of mixed-income housing are as follows: (1) individual households living in the development, and (2) the neighborhood context in which the development is located.

\section{Empirical}

Prior empirical studies of mixed-income housing find mixed benefits and drawbacks for lowerincome and higher-income residents. 
Research based on six case studies from Australian public housing estates indicates that housing policy (1) seeks to reduce the concentration of public housing and create mixed-income communities in order to help connect previously socially excluded public housing residents to society; and (2) is predicated on the idea that a balanced social mix is necessary for developing inclusive and cohesive communities. But the case studies suggest that cohesive communities are already in place and predate mixed-income development, which suggests that balanced social mixes are not required (Arthurson, 2002).

In New South Wales, Australia, social mix involves integrating public housing tenants into places that are mostly occupied by private owners and private renters. An in-depth case study finds that public housing tenants face stigma, oppression, and treatment as "the other" (Ruming et al., 2004).

Based on interviews and ethnographic participant observation, a case study of mixed-income housing in Toronto finds some residents were not satisfied with changes in housing quality, neighborhood planning, and social relations (August, 2016). The former Don Mount Court, now named Rivertowne, was the first redevelopment of public housing into mixed-income housing in Canada. Some public housing tenants longed for their previous homes and were unhappy about the loss of previous community connections. They also reported tense social interactions and relationships with higher-income residents.

A study of owners and renters in three Scottish estates finds that they occupy different social worlds. New housing for owner occupation has little effect on social networks of renters (Atkinson and Kintrea, 2000).

A thorough study of selected sites of mixed-income redevelopment of public housing in Chicago finds that low-income residents are pleased with some of the physical aspects of redevelopment, including the substantial improvement in housing quality compared to the previously existing public housing (Chaskin and Joseph, 2015). However, there is little evidence of the type of social interactions associated with the theorized benefits of mixed-income housing. Instead, poor residents report they have developed few meaningful social relationships with their wealthier neighbors. Further, they experience differential treatment from higher-income residents and building management personnel, despite living in the same building, a situation the authors describe as incorporated exclusion.

\section{Framework and Discussion}

Mixed-income housing appears to be a simple, straightforward idea, but it encompasses many complicated factors and forces at work. The conceptual framework outlined below helps in understanding mixed-income housing by unpacking some of its constituent elements. A key point is that the framework clearly highlights the importance of considering the dynamic process of creating mixed-income housing.

\section{Households}

By construction, mixed-income housing entails bringing households of different income levels together. Some of these households are considered low-income households - in the United States context, the conventional threshold for the low-income category is households with incomes that are less than $80 \%$ of the AMI (US HUD, 1998). These households may experience different forms of material hardship, such as not having enough money to pay for basic needs, including food, going to see a doctor or going to the hospital, and paying rent (Shamsuddin and Campbell, 2021). Low-income households may be employed, receiving 
government benefits, or some combination. However, there is the risk of economic instability due to at-will employment, work schedule changes, and reduction or loss of benefits (Hill et al., 2017). Low incomes may also mean that these households have little or no savings to draw upon in the event of an unexpected event, such as job loss, eviction, or a car breaking down (Board of Governors, 2018). Low-income households may live in low-quality housing, deteriorated units in serious need of repairs, or overcrowded conditions (Watson et al., 2020). Their housing may be located in neighborhoods that are economically declining and distant from employment opportunities. Households that are searching for or already receive a rental housing subsidy may feel constrained to live in public housing or other affordable housingand the neighborhoods in which they are located-in order to ensure continued receipt of the rent subsidy. For these households, mixed-income housing may be one of the few options available to them.

Higher-income households typically have more resources at their disposal and better access to resources than their low-income counterparts. Although there is no standard litmus test for high income, these households in the United States may have incomes that are $200 \%$ of the AMI or even higher. They can comfortably afford to pay market-rate prices for housing and still have plenty of money remaining to pay for basic necessities like food and health care, in addition to purchasing non-essential items. These households are typically employed, often with two wage earners, and may have other sources of income from investments. These households often have high education levels that lead to stable employment positions with many benefits. Higher-income households may live in high-quality housing, new or recently updated units, with spacious accommodations. Their housing is often located in neighborhoods with many educational, cultural, and social amenities. Higher-income households generally have their choice of housing options and neighborhoods in which to live. These households may be motivated to live in mixed-income housing because it is underpriced compared to other market-rate housing or they view themselves as "urban pioneers." In the case of homeownership in mixed-income housing, higher-income households may intend to use the unit as a second home, convert the unit to short- or long-term rental as an additional source of income, or engage in property flipping by quickly reselling the unit after an increase in value.

\section{Moving}

In order to bring households of different incomes together, mixed-income housing typically involves households moving. In some cases, low-income households are the ones who move; in other cases, higher-incomes households are the ones who move; sometimes both groups move. Low-income households may feel compelled or forced to move because of the opportunity to obtain or continue receiving a subsidy. Further, there may be few options in the private housing market, and they might be prohibitively expensive. Higher-income households may deliberately elect or voluntarily wish to move for investment purposes or other reasons. The move itself has costs that can be both financial and psychological. For some households, moving can elicit a feeling of uprooting and displacement, which can be heightened if the move is perceived as forced or not by choice. Also, moving may be precipitated by individual circumstances, such as family formation, dissolution, or other changes in family composition. It is also worth noting that some mixed-income housing is developed on sites that previously contained low-income housing that was subsequently demolished, so mixed-income housing may entail multiple moves for some households. Moving may involve relocating to a completely new and unfamiliar area or it may be a move to a neighborhood that is a known quantity. In some cases, moves may result in a return to a neighborhood where the households previously lived. Generally speaking, 
moves are associated with different types of social relationships that are weakened or severed and expected to be repaired, maintained, or reconstructed.

\section{Housing}

Mixed-income housing also involves the physical component of the housing that is constructed and its associated programmatic aspects. As noted earlier, prior work indicates there are four important dimensions in considering mixed-income housing projects: (1) allocation, (2) proximity, (3) tenure, and (4) duration. Allocation refers to the distribution of units by subsidy type. Proximity refers to the spatial separation of income mix. Tenure refers to the distribution of homeownership versus rental units. Duration refers to the time limits for subsidies that preserve the income mix. In addition, there are other housing project factors that are important to consider. These include development size, building type, and rate of resident return.

\section{Neighborhood}

Finally, mixed-income housing is situated within the geographic context of a specific place or neighborhood. The neighborhood may have multiple characteristics that are important for residents and can influence the outcomes of mixed-income housing. Some neighborhoods may contain or be close to a wide range of employment options that match the skills and interests of residents. Other neighborhoods may feature education and training opportunities for occupational and personal advancement. Neighborhoods may be distinguished by access to public transportation as an affordable means for travel between home, work, school, and other destinations. The presence of or proximity to community institutions, houses of worship, social organizations, parks, and places for recreation may also be important.

The conceptual framework brings these constitutive elements together. It considers household income, the moving process, and the neighborhood context, in addition to the housing itself. It also forces us to identify and examine key differences between various approaches to mixed-income housing. The framework can be visualized using a diagram. See Figure 7.1.

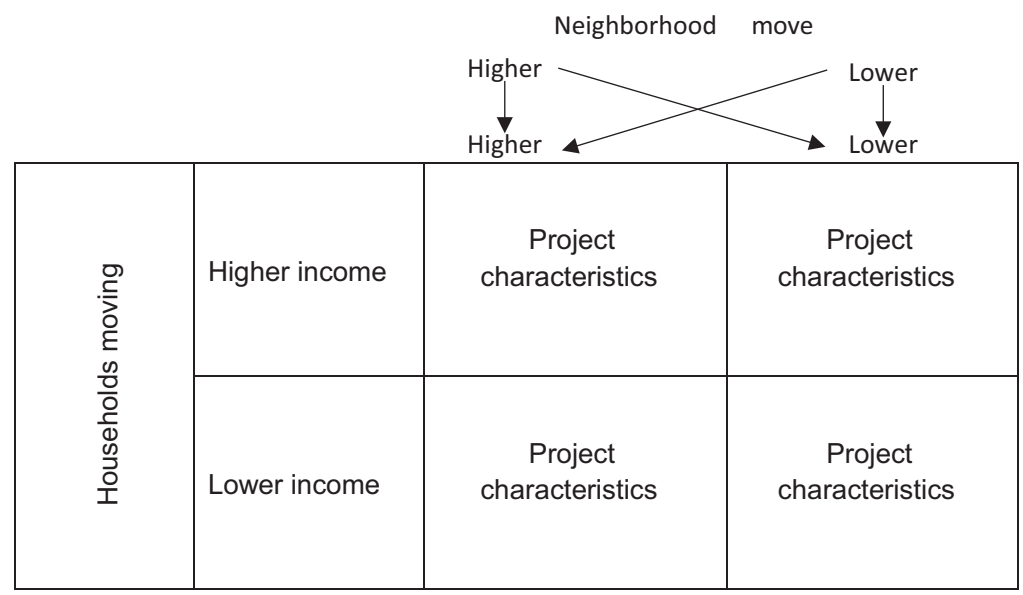

FIGURE 7.1 Income Mixing Conceptual Framework.

Source: Author. 
The framework describes how lower-income households may move from higher-income neighborhoods to other higher-income neighborhoods or to lower-income neighborhoods. Or lower-income households may move from lower-income neighborhoods to other lower-income neighborhoods or to higher-income neighborhoods. Similarly, higher-income households may make the same kinds of moves from and to higher- or lower-income neighborhoods.

It is worth pointing out that in the study of mixed-income housing, interest is typically devoted to two types of moves: from lower-income neighborhoods to higher-income neighborhoods or from higher-income neighborhoods to lower-income neighborhoods. However, some families - more often poor households - make moves from one lower-income neighborhood to another lower-income neighborhood. Similarly, other families-mostly wealthy householdsmake moves from one higher-income neighborhood to another higher-income neighborhood.

As indicated in the figure, project-level variables such as allocation, proximity, tenure, and duration are embedded within the conceptual framework. These building characteristics may influence the frequency and degree of interactions between households. But those dimensions are not the only characteristics that affect the outcomes of mixed-income housing. The framework highlights the importance of considering the characteristics, for example, income of the individual households involved and their position relative to other households. Similarly, the framework makes clear that households and housing projects are situated within a neighborhood context that may influence mixed-income housing outcomes.

A shorthand description of the framework can be formulated as "who is moved where?". This apparently simple question incorporates a series of questions that are expanded upon below:

- What are the incomes of the individual households involved in the mixed-income housing? We would expect households at different income levels to have some differences in their concerns and expectations.

- Are they relatively high-income households or low-income households? How poor are the poor households? For low-income households, are they considered very low-income (less than $50 \%$ of AMI) or extremely low-income (less than 30\% of AMI)?

- Which households are the ones moving?

- Why are they moving or being moved? Are the moves completely voluntary or are they forced? How are the moves incentivized, if at all? Are the moves part of a speculative financial investment or due to financial necessity?

- Where are the individual households moving?

- What is the distribution of units by subsidy type (allocation) in the mixed-income housing project?

- What is the spatial separation of income mix (proximity) in the mixed-income housing project?

- What is the distribution of homeownership versus rental units (tenure) in the mixedincome housing project?

- What are the time limits for subsidies that preserve the income mix (duration) in the mixed-income housing project?

- How does the median income of the destination neighborhood compare with the median income of the origin neighborhood? Is there a substantial increase or decrease in neighborhood income?

Note that there are many other questions that could be asked related to the framework that may influence household outcomes. For example, how long did the household live in the origin neighborhood prior to moving? At what life cycle stage or age did the household move (e.g. 
before having children, with young children, children have left the house, working, retired)? How far (i.e. physical distance) did the household move? For the purposes of this chapter, I treat these as secondary questions.

The attention to moves acknowledges the fact that many types of social relationships are embedded in places. Households often locate in close proximity to family and friends. Residents typically form connections with their immediate (i.e. adjacent) neighbors and other residents in their neighborhood. Residents also attend or participate in local institutions or social organizations, including churches or other houses of worship, community and volunteer groups, ethnic organizations, neighborhood improvement groups, and civic associations. Individuals establish social ties with local providers of goods and services, for example, groceries, beauty and personal care, and retail.

The framework considers the income of households relative to other households and the level of neighborhood income of origin and destination locations for households that move. The attention to income in the framework is a reflection of the attention to income in housing strategies. Affordable housing programs are means tested, that is, eligibility is determined by income level. The construction of mixed-income housing is predicated on the idea of bringing households of different income levels to live together in the same location. In addition, differences in income can be a useful proxy for social distance and are associated with other relevant characteristics.

For various reasons, perhaps including a conscious decision to avoid directly addressing more contentious issues like race, policymakers in the United States have fixated on income. In the United Kingdom and other places, it is more common to discuss social mix instead of mixedincome. The distinction is subtle but has important implications. At one level, social mix explicitly acknowledges that there may be more factors to consider than simply income when encouraging different households to live in close proximity to each other. At another level, social mix emphasizes the importance of social relations that are intended to be fostered between different households. Note that the framework is flexible enough to replace income with other variables. For example, we might be more interested in educational attainment than in income in the housing mix. Then we can simply examine the number of years of schooling for households, as it compares with the population, and the mean or median years of schooling in the origin and destination neighborhoods. Similar substitutions can be made with employment level, occupational status, wealth (as distinct from income), or race and racial composition. In addition, the framework can accommodate indices that combine various measures, such as socioeconomic status.

If housing characteristics are set aside for a moment, then the framework brings households and neighborhood characteristics to the forefront. (For ease of exposition and in the interests of clarity, the following figures focus only on the destination neighborhood and therefore omit the origin neighborhood context.) The various combinations of these characteristics can provide a crosswalk for policy problems and scholarly criticisms that have emerged from prior iterations of housing policies and programs, as well as the stated policy goals of housing programs that seek to address past problems. See Figure 7.2.

Researchers and analysts have raised concerns that higher-income households exclusively moving to higher-income neighborhoods will, over time, lead to increased residential segregation by income. These types of housing practices may reinforce various types of social and political exclusion of low-income households. In many countries, residential income segregation of wealthy households naturally emerges from the operation of the private housing market. In the United States, one concrete and visible manifestation of residential income segregation and exclusion is the existence of gated housing communities. 


\begin{tabular}{|c|c|c|c|}
\hline & & \multicolumn{2}{|c|}{ Neighborhood } \\
\hline & & Higher income & Lower income \\
\hline \multirow{2}{*}{ 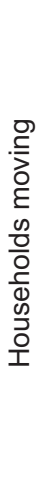 } & Higher income & $\begin{array}{l}\text { (-) Income segregation } \\
\text { and exclusion }\end{array}$ & $\begin{array}{l}\text { (+) Reinvestment and } \\
\text { revitalization } \\
\text { (-) Gentrification and } \\
\text { displacement }\end{array}$ \\
\hline & Lower income & $\begin{array}{l}\text { (+) Access to } \\
\text { opportunity } \\
\text { (-) Fears of } \\
\text { neighborhood tipping } \\
\text { and decline }\end{array}$ & (-) Poverty concentration \\
\hline
\end{tabular}

FIGURE 7.2 Crosswalk for Housing Policy Goals and Problems.

Source: Author.

Residential income segregation can also operate at the other end of the income spectrum, but this may be less often due to the choice of these households. Observers have suggested that the continual move of lower-income households to lower-income neighborhoods leads to the concentration of poor households. Some policymakers assert that concentrated poverty results in a range of social problems, including unemployment, childbirth out of wedlock, drug use, and crime. Indeed, many forms of mixed-income housing seek to address the social problems associated with the concentration of poor households in public housing.

It is interesting to note that policymakers rarely see any advantages or benefits to lowerincome households moving to lower-income neighborhoods, despite decades of public policynot only housing policy but others too-that have encouraged this very situation. However, academic research has pointed out the deep interpersonal relationships, high levels of social capital, and strong social networks and sense of community found among lower-income households living in lower-income neighborhoods (for example, see Saegert et al., 2002).

Analyzing income mixing in terms of differences between households and between neighborhoods also helps in understanding and predicting the effects on residents of mixed-income housing in its various forms. We can and should expect different effects based on household and neighborhood characteristics, in addition to project-level dimensions.

Households and neighborhood characteristics in the framework can also help distinguish between various forms of housing policy and approaches to creating income mixes in housing. These policies and approaches include public or social housing, Housing Choice Vouchers (also known as Section 8), public housing redevelopment into mixed-income housing projects as in the HOPE VI program, the Moving to Opportunity for Fair Housing program, Low-Income Housing Tax Credit developments, inclusionary zoning and inclusionary housing, and others. These policies can be arrayed across the major categories outlined in the framework: (1) lower-income households moving (back) to lower-income neighborhoods, (2) lower-income households moving to higher-income neighborhoods, and (3) higher-income households moving to lower-income neighborhoods. (The fourth category, higher-income households moving to higher-income neighborhoods describes usual activity in the private housing market but does not generally apply to typical, existing mixed-income housing strategies). See Figure 7.3. 
Neighborhood

Higher income

Lower income

\begin{tabular}{|c|c|c|c|}
\hline ర) & Higher income & $\begin{array}{l}\text { - } \text { [Private housing } \\
\text { market] }\end{array}$ & $\begin{array}{l}\text { - Conventional view } \\
\text { of HOPE VI } \\
\text { redevelopment }\end{array}$ \\
\hline 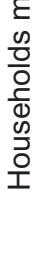 & Lower income & $\begin{array}{l}\text { - Moving to } \\
\text { Opportunity } \\
\text { treatment group } \\
\text { - Inclusionary } \\
\text { zoning in strong } \\
\text { housing markets }\end{array}$ & $\begin{array}{l}\text { - Traditional Public } \\
\text { Housing } \\
\text { - Typical Housing } \\
\text { Choice Voucher } \\
\text { use }\end{array}$ \\
\hline
\end{tabular}

FIGURE 7.3 Categorizing Housing Policies.

Source: Author.

Housing policies and programs to create income mixing take different forms even though they are often categorized under the common umbrella term of mixed-income housing. Some of these differences are brought to the foreground when examined in terms of household incomes, who moves, and the neighborhood context. Figure 7.3 enables and suggests how scholars might approach an "apples to apples" comparison of mixed-income housing strategies.

In many academic discussions, the terms "mixed-income housing" or "mixed-income development" have become synonymous with the transformation of deteriorated public housing projects into residential developments that house people with a range of incomes, including low-income, public housing eligible households. However, public housing redevelopment is not the only form of mixed-income housing.

"Mixed-income" is frequently employed as a signal or description of the existence of residential unit subsidies in a given housing development project. Further, the term "mixed-income housing" places emphasis on the building or residential unit as the chief product of the development process. It implies that the physical structure is the end result and primary outcome of interest. All of these combine to suggest a static view of what is involved in mixed-income housing. However, the theorized impact of mixed-income housing crucially depends on how households from different groups interact and mix together. To help redirect our attention to households and the dynamics involved-and to draw a distinction from mixed-income housing - the term "income mixing" is introduced and used. Income mixing (or social mixing) is the process or strategy of bringing households from different income groups to live together in the same location. The process fundamentally depends on moving people of different income levels from one place to another.

The term "income mixing" is also employed because it more easily accommodates different forms of creating mixed-income housing, including tenant-based subsidies, financial incentives for construction, and local regulations about the composition of new development. Income mixing is about the type and nature of interactions between residents. It indicates the importance of social relationships in evaluating housing that brings different income groups together.

There are some limitations and additional considerations to keep in mind with regard to the conceptual framework presented here. As noted earlier, there are many possible variables to 
consider beyond income. Social relationships are complex and can depend on a complex set of factors. Further, the framework highlights that income mixing is a dynamic process. Similarly, households, housing development composition, and neighborhoods are not static. To take a simple example, resident incomes and neighborhoods can change over time. These changes may affect the nature of content of the social relationships involved.

Despite these limitations, more careful consideration of who is moved where may lead us to revise our expectations about different forms of mixed-income housing and help explain the observed effects on residents.

\section{Acknowledgments}

The author would like to thank Mark Joseph for helpful conversations that prompted this chapter, Sasha Tsenkova for creating and organizing the symposium, and Larry Vale for advice and guidance.

\section{References}

Arthurson, K. (2002) Creating inclusive communities through balancing social mix: A critical relationship or tenuous link? Urban Policy and Research, 20(3): 245-261.

Atkinson, R., and Kintrea, K. (2000) Owner-occupation, social mix and neighbourhood impacts. Policy \& Politics, 28(1): 93-108.

August, M. (2008) Social mix and Canadian public housing redevelopment: Experiences in Toronto. Canadian Journal of Urban Research, 17(1): 82-100.

August, M. (2016) Revitalisation gone wrong: Mixed-income public housing redevelopment in Toronto's Don Mount Court. Urban Studies, 53(16): 3405-3422.

Bailey, N., Haworth, A., Manzi, T., et al. (2006) Creating and sustaining mixed income communities. Coventry: Chartered Institute of Housing/Joseph Rowntree Foundation.

Baron, R. D. (2009) “The evolution of HOPE VI as a development program.” In Cisneros, H. and Engdahl, L. (eds). From despair to hope: HOPE VI and the new promise of public housing in America's cities. Washington, DC: Brookings Institution Press, 31-46.

Board of Governors of the Federal Reserve System. (2018) Report on the economic well-being of U.S. Households in 2017. Washington, DC: Federal Reserve Board.

Bridge, G., and Butler, T. (eds). (2011) Mixed communities: Gentrification by stealth? Bristol: Policy Press.

Brophy, P. C., and Smith, R. N. (1997) Mixed-income housing: Factors for success. Cityscape, 3(2): 3-31.

Chaskin, R., and Joseph, M. (2015) Integrating the inner city: The promise and perils of mixed-income public housing transformation. Chicago, IL: The University of Chicago Press.

Cisneros, H., and Engdahl, L. (eds). (2009) From despair to hope: HOPE VI and the new promise of public housing in America's cities. Washington, DC: Brookings Institution Press.

Cuomo, A. (1999) HOPE VI: Building communities transforming lives. Washington, DC: U.S. Department of Housing and Urban Development.

Darcy, M. (2010) De-concentration of disadvantage and mixed income housing: A critical discourse approach. Housing, Theory and Society, 27(1): 1-22.

Epp, G. (1996) Emerging strategies for revitalizing public housing communities. Housing Policy Debate, 7(3): 563-587.

Harper, J. (2017) How mixed-income housing can benefit both communities and investors. Urban Land Magazine. September 18.

Hill, H. D., Romich, J., Mattingly, M. J., Shamsuddin, S., and Wething, H. (2017) An introduction to household economic instability and social policy. Social Service Review, 91(3): 371-389.

Holin, M. J., Buron, L., Locke, G., and Cortes, A. (2003) Interim assessment of the HOPE VI program crosssite report. Bethesda, MD: Abt Associates Inc.

Joseph, M. L., Chaskin, R. J., and Webber, H. S. (2007) The theoretical basis for addressing poverty through mixed-income development. Urban Affairs Review, 42(1): 369-409. 
Kearns, A., and Mason, P. (2007) Mixed tenure communities and neighbourhood quality. Housing Studies, 22(5): 661-691.

Khadduri, J., and Martin, M. (1997) Mixed-income housing in the HUD multifamily stock. Cityscape, 3(2): 33-69.

Kleit, R. G. (2005) HOPE VI new communities: Neighborhood relationships in mixed-income housing. Environment and Planning A, 37(8): 1413-1441.

Levy, D. K., McDade, Z., and Dumlao, K. (2010) Effects from living in mixed-income communities for lowincome families: A review of the literature. Washington, DC: Urban Institute.

Metropolitan Council. (2019) Support for mixed income housing development: Resources for communities to explore mixed income housing possibilities. https://metrocouncil.org/Housing/Projects/ Mixed-Income-Housing-Calculator.aspx, accessed June 12, 2019.

Musterd, S., and Andersson, R. (2005) Housing mix, social mix, and social opportunities. Urban Affairs Review, 40(6): 761-790.

Popkin, S. J., Katz, B., Cunningham, M. K., Brown, K. D., Gustafson, J., and Turner, M. A. (2004) A decade of HOPE VI: Research findings and policy challenges. Washington, DC: Urban Institute.

Ruming, K. J., Mee, K. J., and McGuirk, P. M. (2004) Questioning the rhetoric of social mix: Courteous community or hidden hostility? Australian Geographical Studies, 42(2): 234-248.

Saegert, S., Thompson, J. P., and Warren, M. R. (eds). (2002) Social capital and poor communities. New York: Russell Sage Foundation.

Schwartz, A., and Tajbakjsh, K. (1997) Mixed-income housing: Unanswered questions. Cityscape, 3(2): 71-92.

Shamsuddin, S. (2017) Preserved for posterity: Public housing redevelopment and replacement in HOPE VI. Paper presented at the Association of Collegiate Schools of Planning (ACSP) annual conference. Denver, CO.

Shamsuddin, S., and Campbell, C. (2021) Housing cost burden, material hardship, and well-being. Housing Policy Debate.

Shamsuddin, S., and Vale, L. J. (2017) Hoping for more: Redeveloping U.S. public housing without marginalizing low-income residents? Housing Studies, 32(2): 225-244.

Tsenkova, S. (2019) Mixed-income affordable housing projects: Experiences in Canadian cities. In Tsenkova, S. (ed) The Future of Affordable Housing. Calgary: University of Calgary/SAPL, pp. 171-187.

US Department of Housing and Urban Development. (1998) Transmittal of fiscal year (FY) 1998 public housing/Section 8 income limits. PDR-98-02.

Vale, L. J. (2013) Purging the poorest: Public housing and the design politics of twice-cleared communities. Chicago, IL: The University of Chicago Press.

Vale, L. J., and Shamsuddin, S. (2014) All mixed up: Defining mixed-income in public housing redevelopment. Paper presented at ISA World Congress of Sociology. Yokohama, Japan.

Vale, L. J., and Shamsuddin, S. (2017) All mixed up: Making sense of mixed-income housing developments. Journal of the American Planning Association, 83(1): 56-67.

Watson, N. E., Steffan, B. L., Martin, M., and Vandenbroucke, D. A. (2020) Worst case housing needs: 2019 report to Congress. Washington, DC: U.S. Department of Housing and Urban Development. 